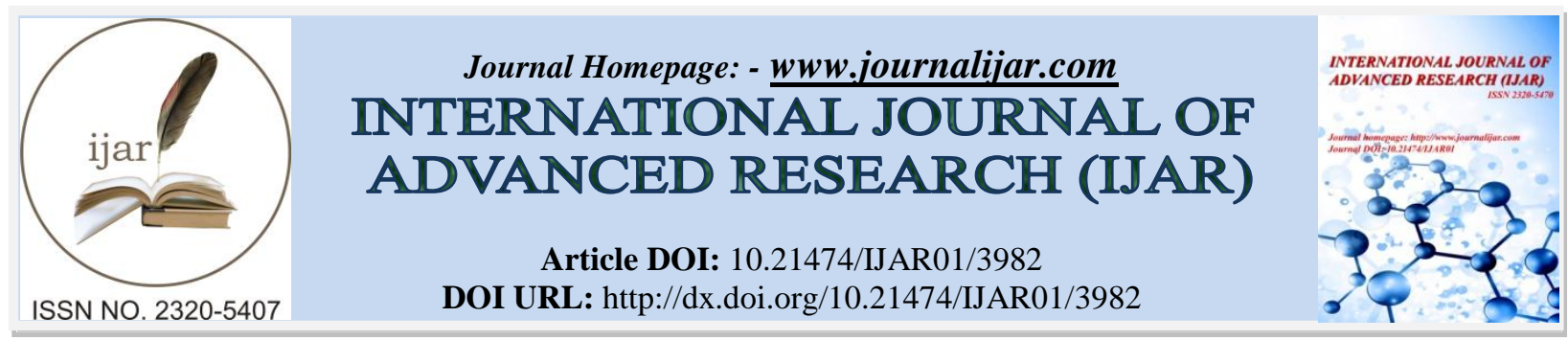

RESEARCH ARTICLE

\title{
MITIGATION OF VOLTAGE DISTRUBANCES IN SMIB SYSTEM USING ANN/FUZZY BASED DPFC SYSTEM.
}

\author{
Budi Srinivasarao $^{1}$, G. Sreenivasan ${ }^{2}$ and Swathi Sharma ${ }^{3}$. \\ 1. Research Scholar, Dept. of EEE, Jodhupur National University, Rajasthan, India \\ 2. Assoc.Prof, Dept. of EEE, Intel Engineering College, Anathapur, A.P, India \\ 3. Assoc.Prof, Dept. of EEE, Jodhupur National University, Rajasthan, India
}

\section{Manuscript Info}

n.........................

Manuscript History

Received: 18 February 2017

Final Accepted: 07 March 2017

Published: April 2017

Key words:-

Power Quality, Sag/Swell, Fuzzy, ANN, FACTS Controllers.

\begin{abstract}
Since last decade, the reliability of power at consumer point is mainly effected due to sudden changes of loads, variations in the system parameters and finally, due to complexity of the system. Generally, power quality is defined as the variations in the voltage, frequency and current. For compensating these problems a new strategy of FACTS controller called as Distributed Power Flow Controller is proposed in this paper. In order to get the better result the control circuit of DPFC is designed with ANN and Fuzzy Controllers.
\end{abstract}

Copy Right, IJAR, 2017,. All rights reserved.

\section{Introduction:-}

By considering the transmission of electrical energy frame creating stations to shopper focuses, the term power quality is utilized to gauge the flawlessness of power and the lattices capacity to supply a reasonable sinusoidal wave shape [1]. At purchaser point the solid power is only, how the transmission line parameters, for example, voltage, current and others are influenced and veered off from their genuine values because of event of aggravations [2].

Generally, flexible ac transmission system gives the good solution for power quality improvement [3]. Facts controllers are classified into four types, i.e Shunt, Series, Series-Series and Series-Shunt controllers. There is general accord that the future power grid tends to be smart and mindful, furthermore, statically controllable and energy efficient.

\section{Working Architecture of DPFC:-}

Like, UPFC controller, DPFC is also one of the type in series-shunt converter of FACTS converter. But, in case of DPFC DC-Link capacitor between series-shunt converters is separated, figure 1 shows the construction and architecture of DPFC. In case of DPFC the active power is exchanged between two converters with the help of transmission line. 


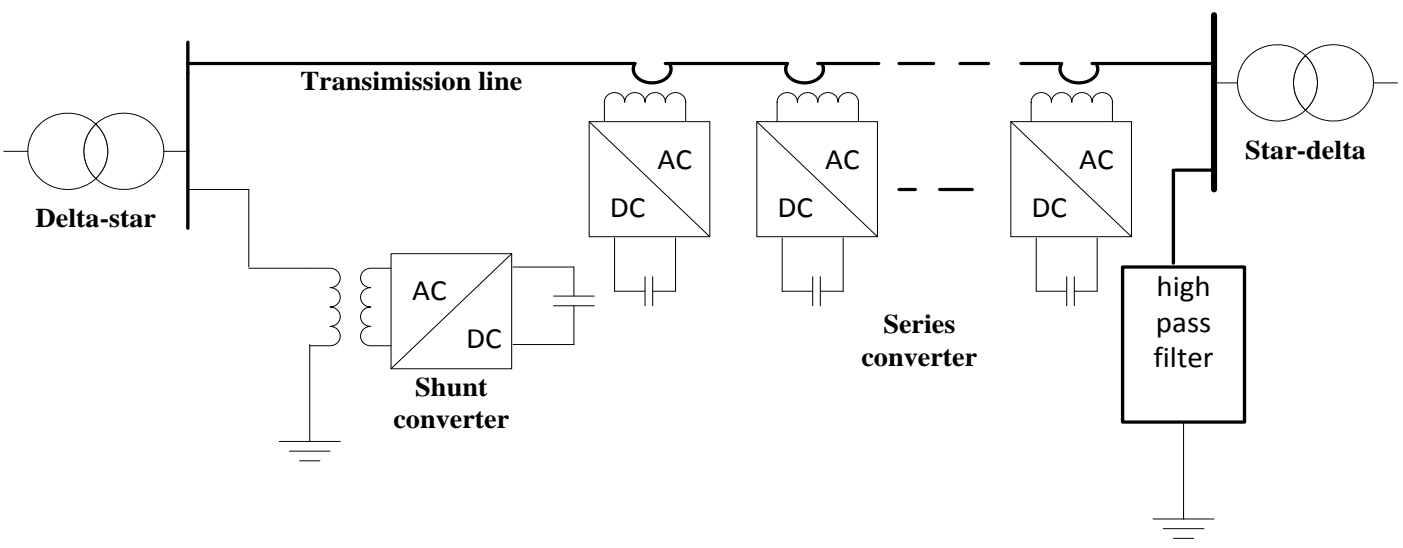

Figure 1:- Working Construction of Distributed Power Flow Controller.

\section{Dpfe Control Circuit:-}

Basically, the control circuit for DPFC is spitted into three parts such as, central controller, shunt and series controllers [7].

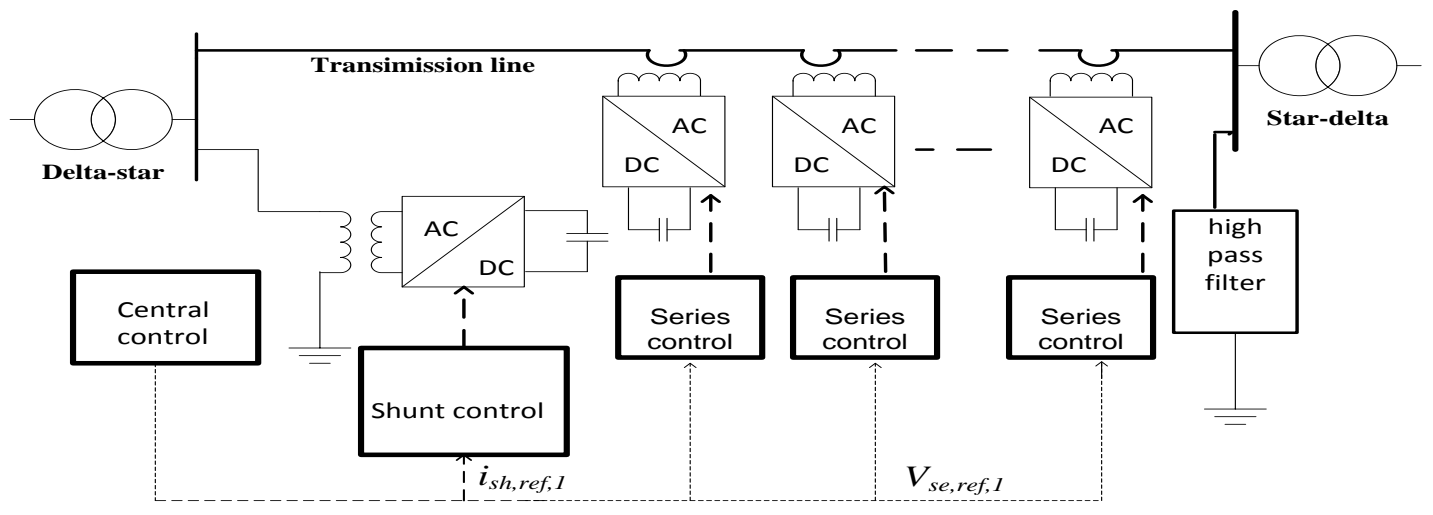

Figure 2:-DPFC Shunt Converter Control Diagram

\section{Series Controller:-}

In series controller a PWM generator is used to control the series converter. The PWM technique reference signal is obtained by comparing the DC-Link voltage and its reference values. In this generic park's transformation (single phase) is also implemented [9]. The control structure for series controller of DPFC is as shown in figure 3.

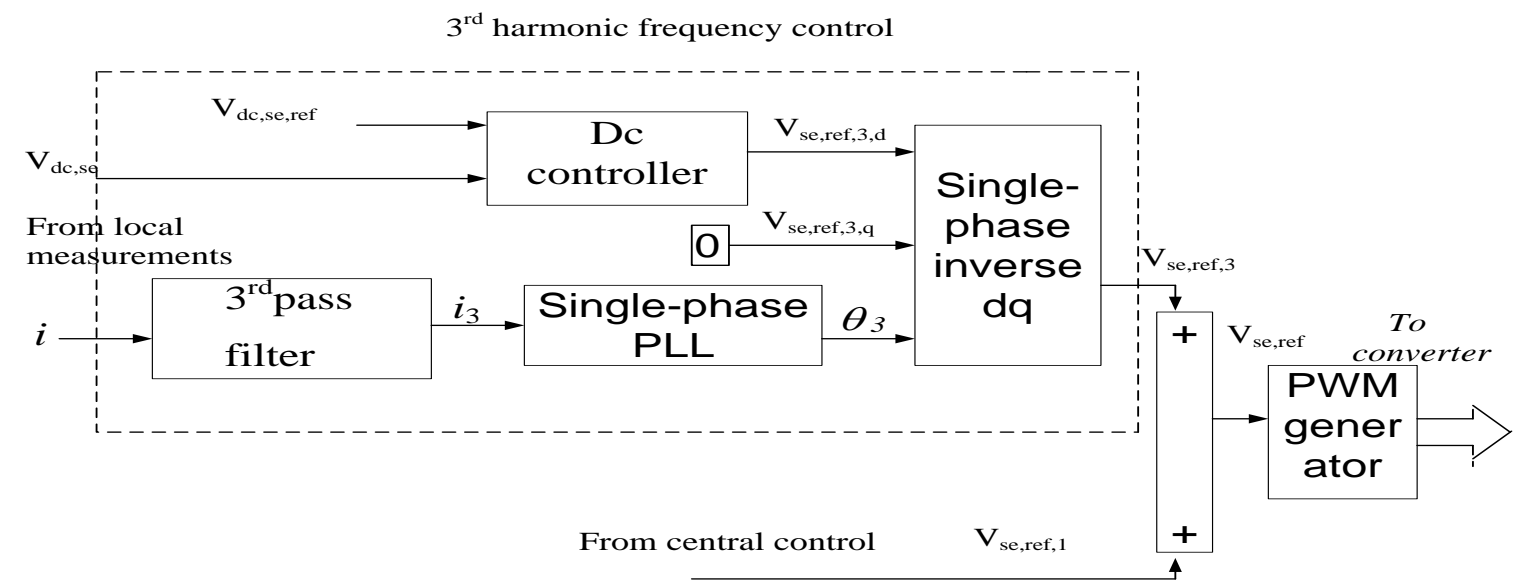

Figure 3:- DPFC Series Converter Control Diagram. 


\section{Parallel Controller:-}

Figure 4 shows the control structure for DPFC shunt converter. This converter consists of two parts i.e one for injecting third order harmonic to the transmission system and second one basic fundamental controller for controlling current harmonics [10]. The PWM technique reference signal is obtained by comparing the DC-Link voltage and its reference signal from the central controller of DPFC. In this generic park's transformation (single phase) is also implemented.

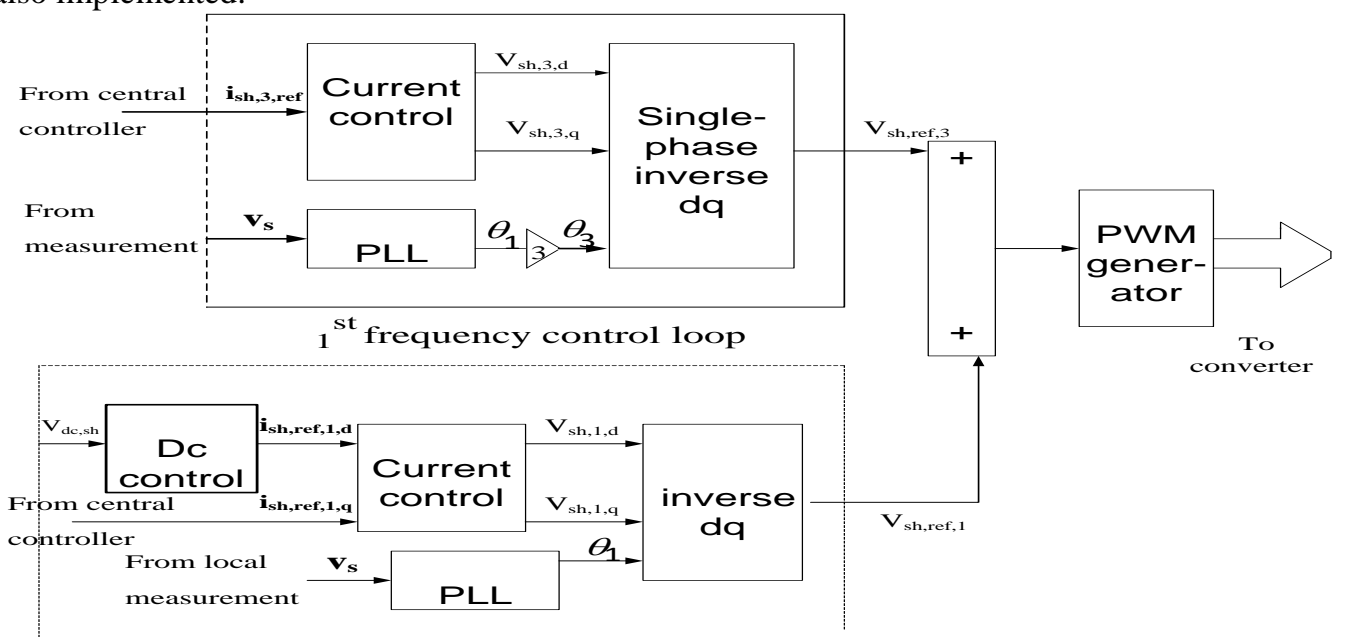

Figure 4:- Control Structure for DPFC Shunt Converter

\section{Artificial Neural Network:-}

The architecture of neural network is shown in figure 5. In this case the number of inputs for neural network is two inputs such as error and rate of change of error. Each input is divided into 5 membership values named as $\{$ MP, SP, $\mathrm{Z}, \mathrm{SN}, \mathrm{MN}$ \}. The rules which is used for designing the ANN is obtained with the help of if-then statements. And a new feedforward network is chosen. After train the feed forward network, the simulation block will generate with the help of 'gensim' command.

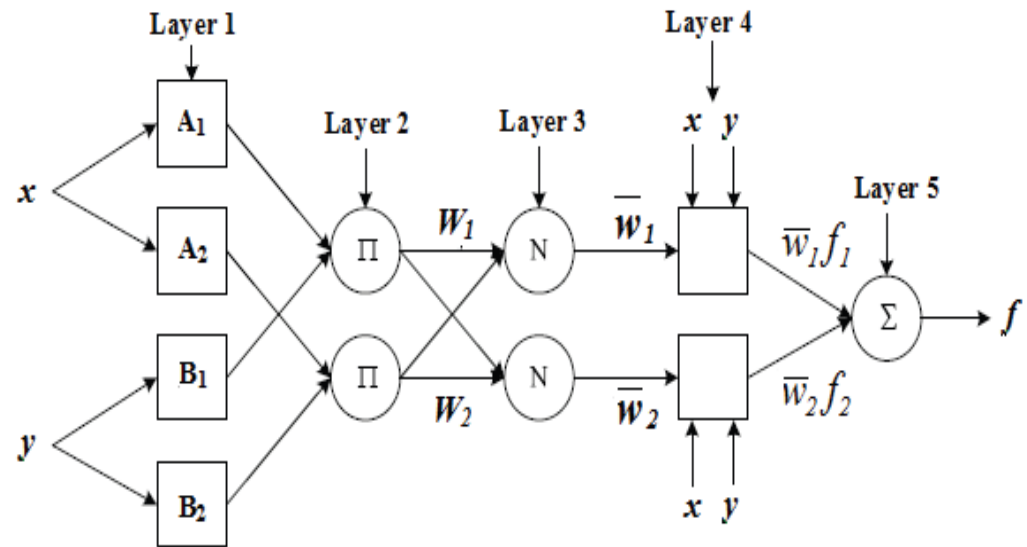

Figure 5:- Architecture of Artificial Neural Network. 


\section{Fuzzy Controller:-}

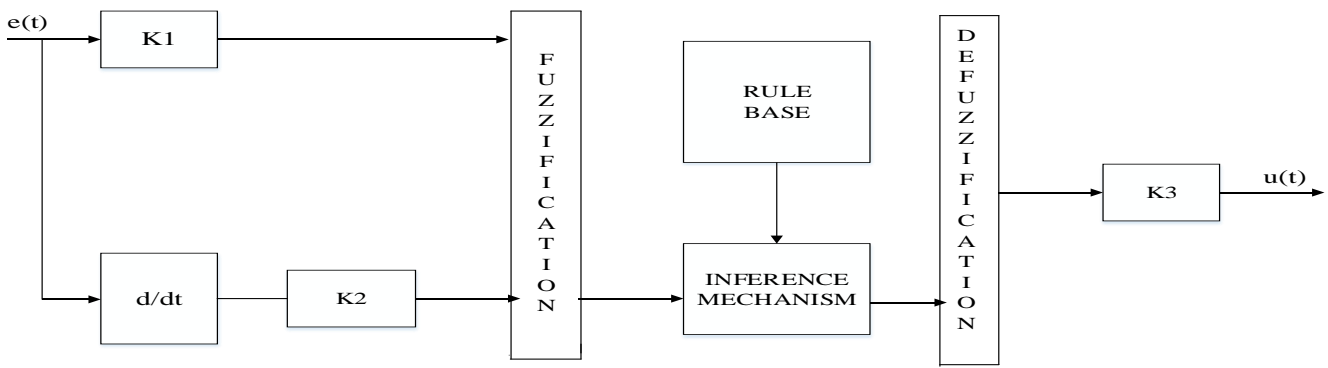

Figure 6:- Fuzzy Mamdani System Configuration

The architecture for fuzzy controller is shown in figure 6. In order to get the better compensation as compared with PI controller a Mamdani based fuzzy controller s proposed in this paper. The given fuzzy inference system is a two input model, generally, it is taken one of the input as error between $\mathrm{Vdc}$ and Vdcref and the second input is rate of change of error. Each input consists of fuzzy set with membership values of $\{\mathrm{MP}, \mathrm{SP}, \mathrm{Z}, \mathrm{SN}, \mathrm{MN}\}$. And it consists total number of rules as 25 . After that a centroid method is used for converting fuzzy set into normal crisp value.

\section{Simulation Diagram And Results:-}

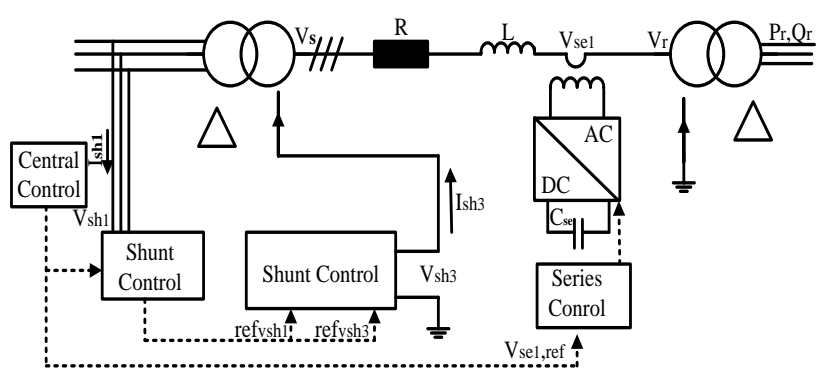

Figure 7:- DPFC Experimental Structure.

The proposed is system as shown in figure 7, is tested under different fault conditions using Fuzzy and Ann controller is tested using Matlab/Simulink. In this paper the fault is applied between the times $500 \mathrm{~ms}$ to $1100 \mathrm{~ms}$.

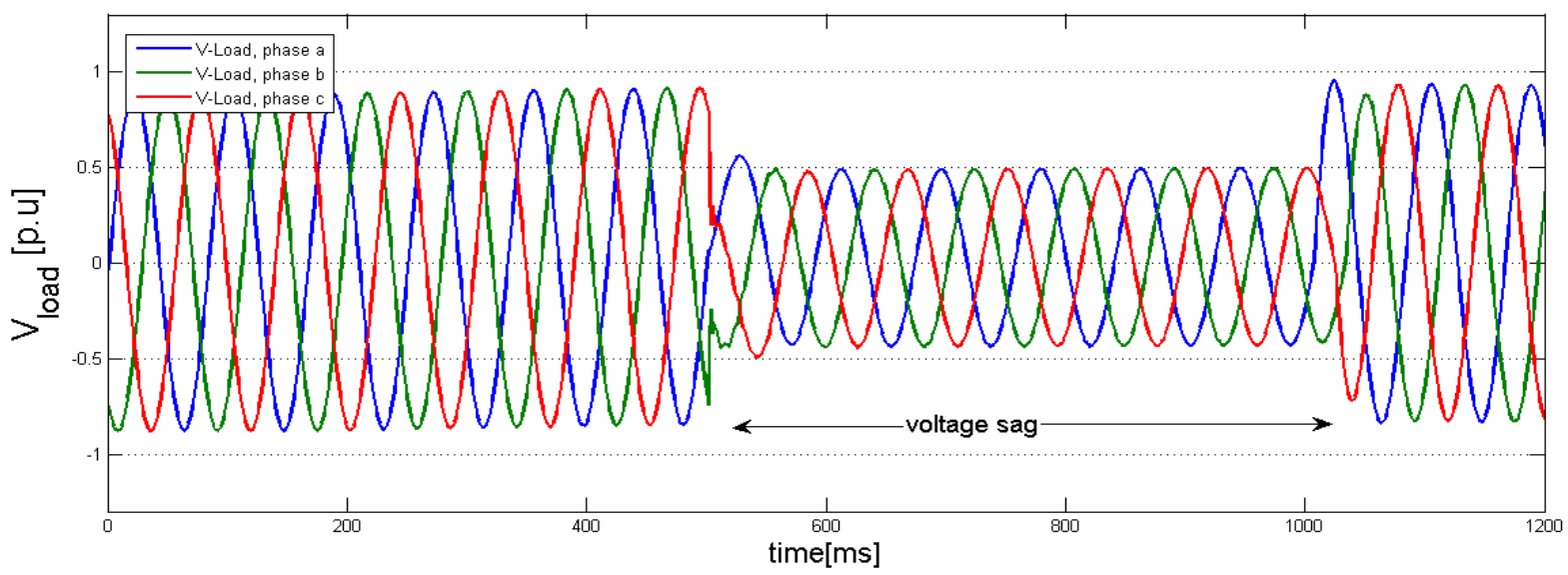

Figure 8:- Load Voltage of SMIB system under fault without DPFC

Above figure 8 shows the simulation result for output load voltage under $3-\otimes$ fault without DPFC controller. During this fault period the output voltage is reduced (sag condition) to $35 \%$ of the rated value. 


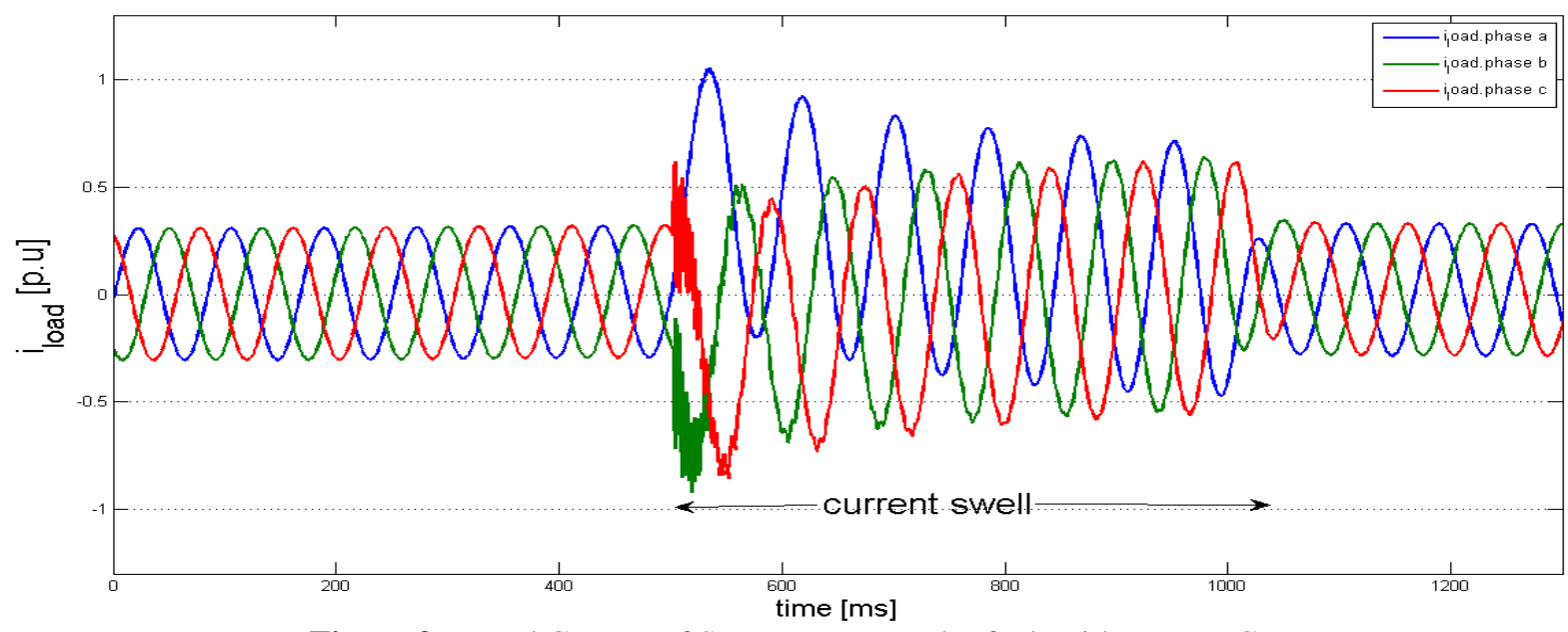

Figure 9:- Load Current of SMIB system under fault without DPFC

Above figure 9 shows the simulation result for output load Current under 3- - fault without DPFC controller. During this fault period the output current is raised (swell condition) to $35 \%$ of the rated value.

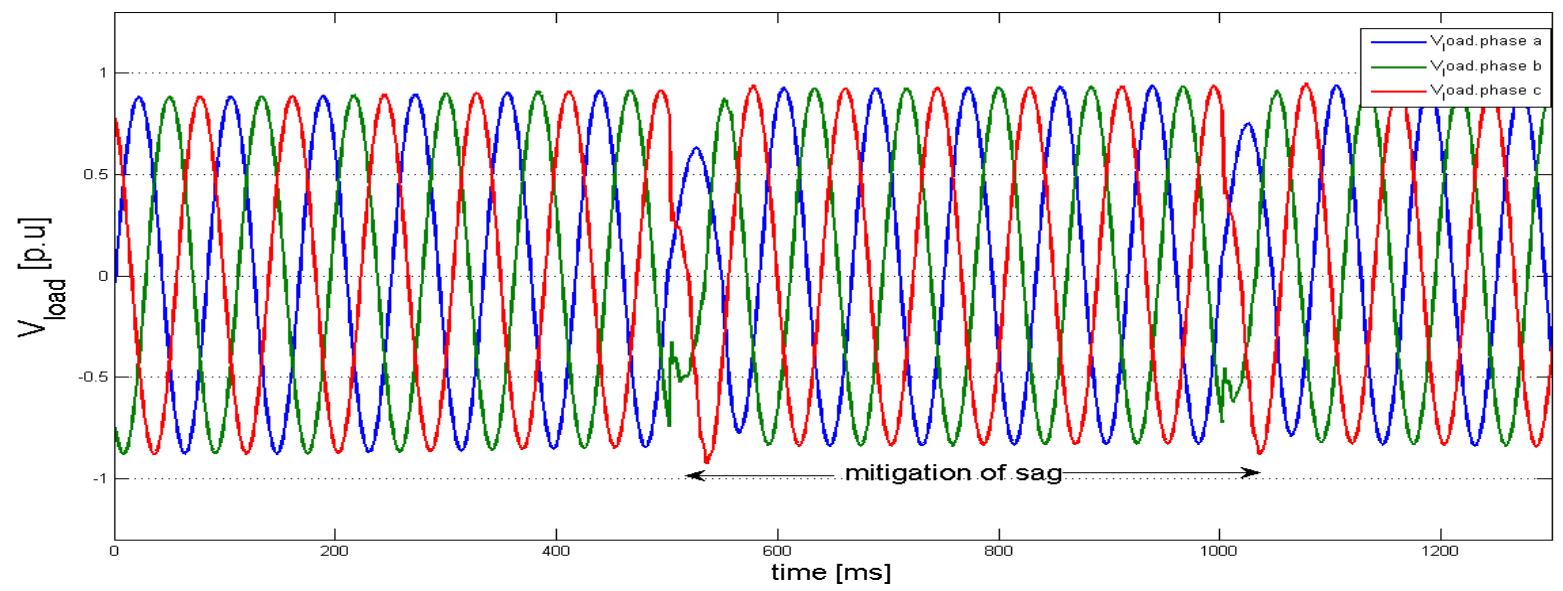

Figure 10:- Load Voltage of SMIB system under fault with DPFC

Above figure 10 shows the simulation result for output load voltage under $3-Q$ fault with DPFC controller. The voltage sag which is occurred during fault condition is compensated successfully with DPFC series converters.

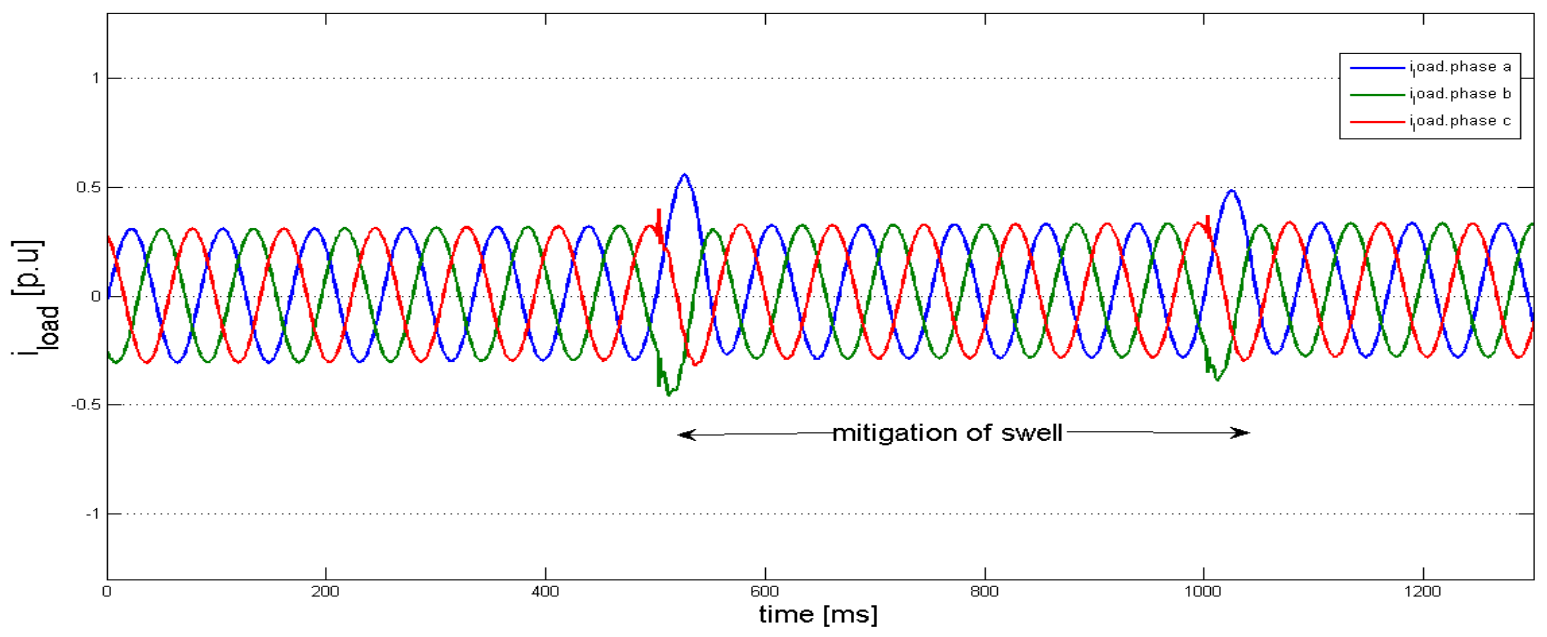

Figure 11:- Load Current of SMIB system under fault with DPFC. 
Above figure 11 shows the simulation result for output load Current under $3-\propto$ fault with DPFC controller. The current swell which is occurred during fault condition is compensated successfully with DPFC series \& shunt converters.

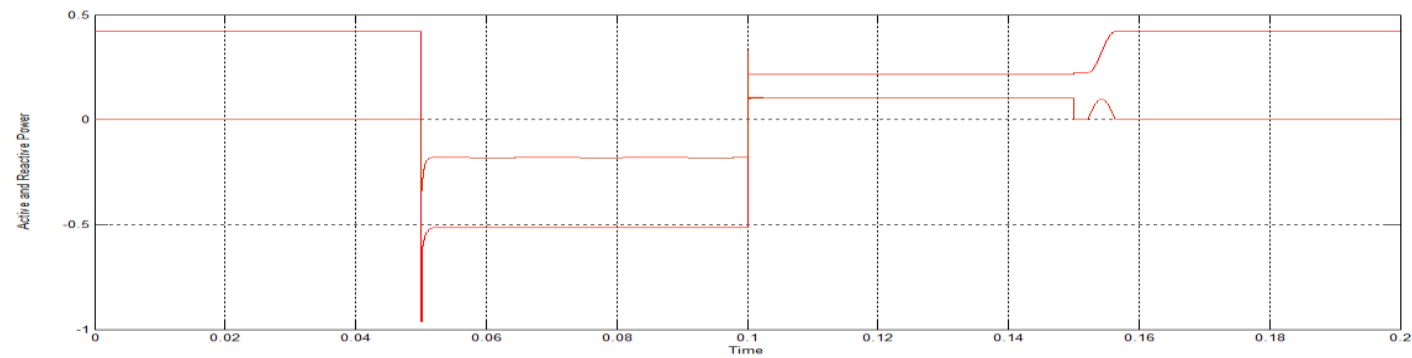

Figure 12:- Active and Reactive Power of Transmission system with DPFC during fault

The flawless desired voltages and harmonic free currents are displayed in the results which demonstrates the capability of the proposed device. The total harmonic distortion factor for this system is verified by using fast Fourier transform analysis. THD value for a system is $12.36 \%$ and it is reduced by using DPFC controller.

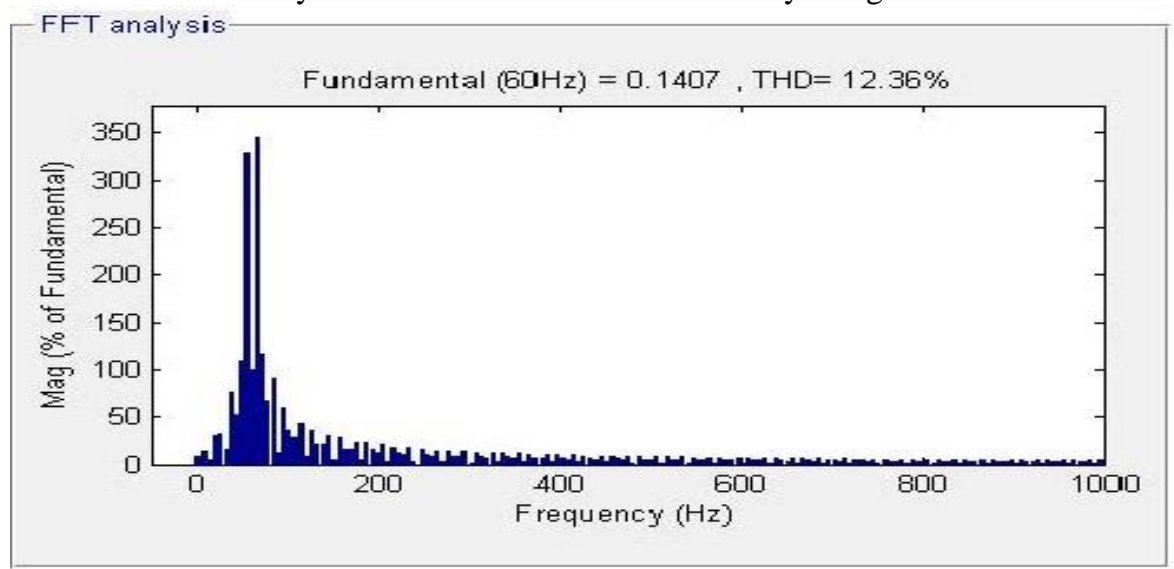

Figure 13:- FFT analysis for load voltage without DPFC

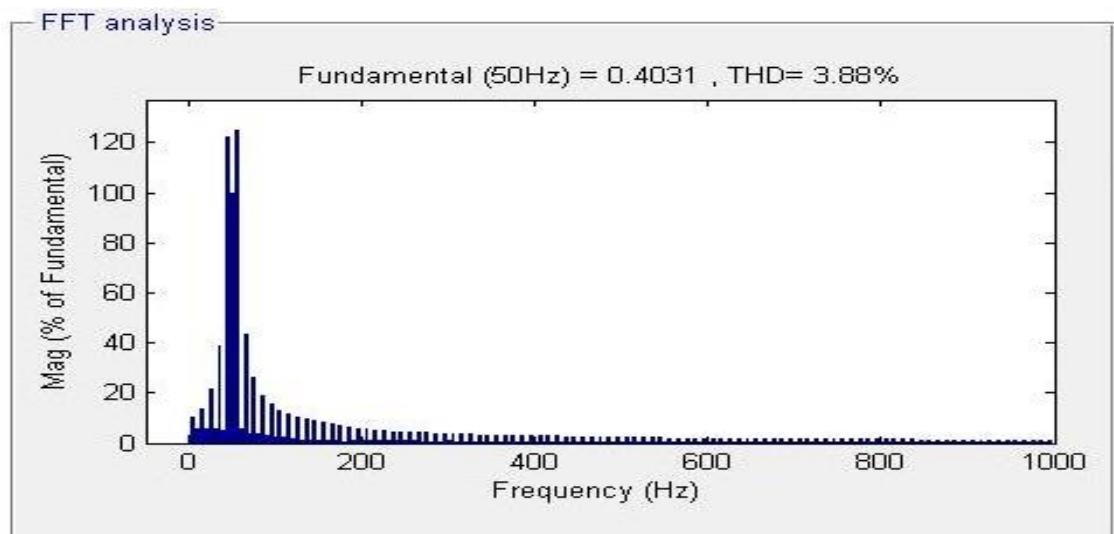

Figure 14:- FFT analysis for load voltage with DPFC 


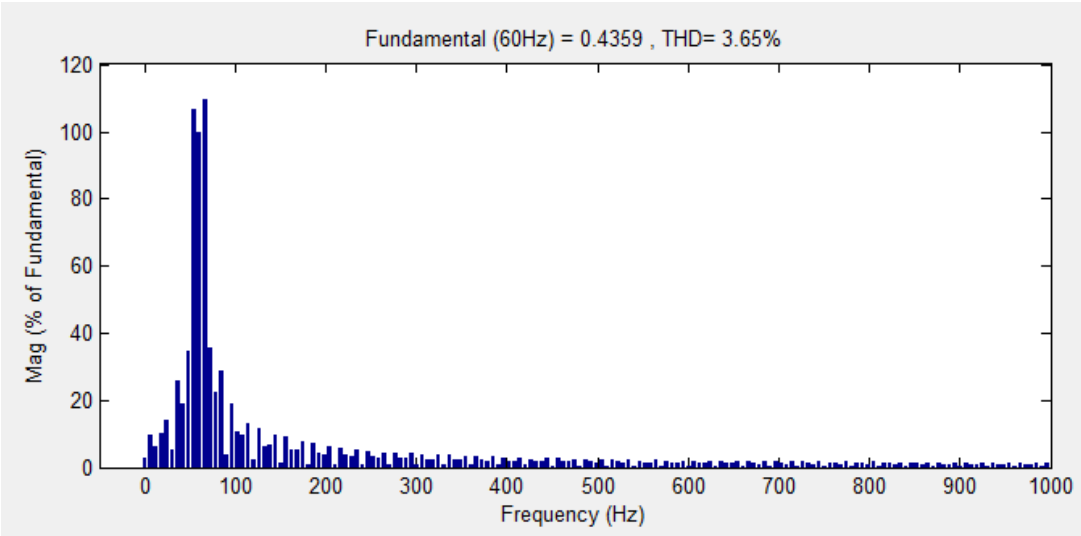

Figure 15:- FFT analysis for load voltage with Fuzzy based DPFC.

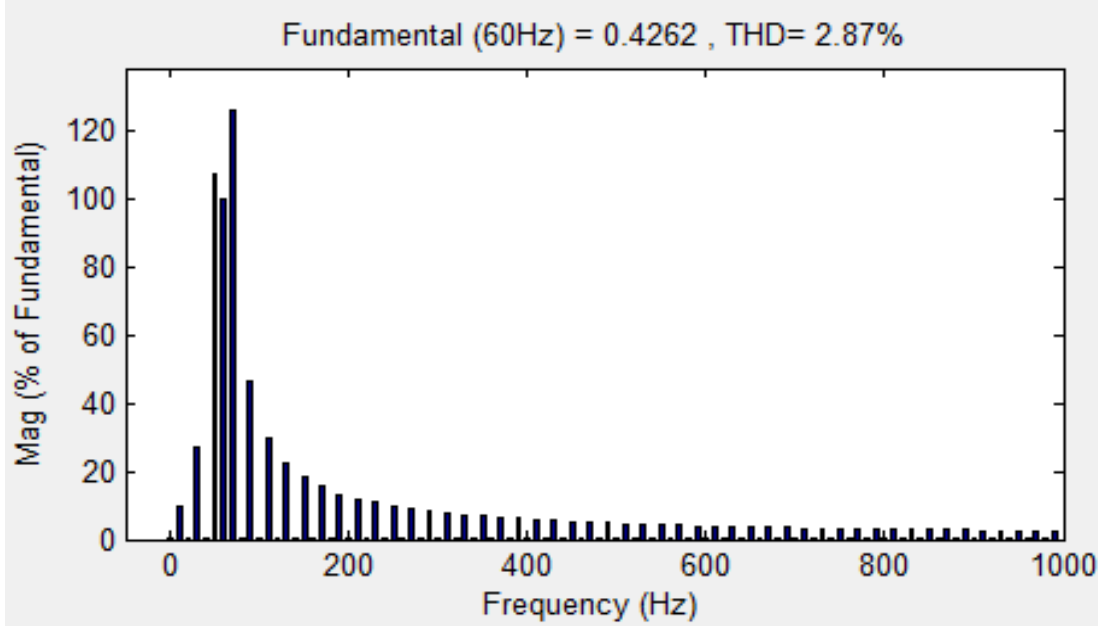

Figure 16:-FFT analysis for load voltage with Neuro based DPFC

Simulated results were obtained for the system using series-shunt converter system with Neuro \& Fuzzy Controller. And the THD content amounting to $2.87 \%$ as shown in figure $15 \& 16$, which is well inside the limits of IEEE 519 standards.

Table 1:- Comparison Of THD Values

\begin{tabular}{|c|c|c|}
\hline S.NO & Name & THD value \\
\hline 1 & Load voltage without DPFC & $12.36 \%$ \\
\hline 2 & Load voltage with DPFC(PI) & $3.88 \%$ \\
\hline 3 & Load voltage with DPFC(Fuzzy) & $3.65 \%$ \\
\hline 4 & Load voltage with DPFC(ANN) & $2.87 \%$ \\
\hline
\end{tabular}

\section{Conclusion:-}

The new concept of FACTS controller called DPFC is successfully implemented for improving power quality. For obtaining better harmonic distortion and Power Quality this paper is extended with both Fuzzy and ANN controllers. i.e the DPFC series and shunt controllers are controlled with FUZZY and ANN controllers instead of conventional PI controller. And from the simulation results, we conclude that ANN based DPFC controller provides the better harmonic distortion factor as compared with Fuzzy and PI controller. 


\section{References:-}

1. D. Divan and H. Johal, "Distributed facts-A new concept for realizing grid power flow control," in IEEE 36th Power Electron. Spec. Conf. (PESC), 2005, pp. 8-14.

2. K K. Sen, "Sssc-static synchronous series compensator: Theory, modeling, and application",IEEE Trans. Power Del., vol. 13, no. 1, pp. 241-246, Jan. 1998.

3. L.Gyugyi, C.D. Schauder, S. L.Williams, T. R. Rietman, D. R. Torgerson, and A. Edris, "The unified power flow controller: A new approach to power transmission control”, IEEE Trans. Power Del., vol. 10, no. 2, pp. 1085- 1097, Apr. 1995.

4. M. D. Deepak, E. B. William, S. S. Robert, K. Bill, W. G. Randal, T. B. Dale, R. I. Michael, and S. G. Ian, “A distributed static series compensator system for realizing active power flow control on existing power lines", IEEE Trans. Power Del., vol. 22, no. 1, pp. 642-649, Jan.2007

5. M. Mohaddes, A. M. Gole, and S. Elez, "Steady state frequency response of statcom", IEEE Trans. Power Del., vol. 16, no. 1, pp. 18-23, Jan. 2001.

6. Y. Zhihui, S.W. H. de Haan, and B. Ferreira, "Utilizing distributed power flow controller (dpfc) for power oscillation damping", in Proc. IEEE Power Energy Soc. Gen. Meet. (PES), 2009, pp. 1-5.

7. Y. Sozer and D. A. Torrey, "Modeling and control of utility interactive inverters",IEEE Trans. Power Electron., vol. 24, no. 11, pp. 2475-2483, Nov. 2009.

8. A. Jamshidi, S. Masoud Barakati and Mohammad Moradi Ghahderijani, "Power quality improvement and mitigation case study using distributed power flow controller," Industrial Electronics (ISIE), 2012 IEEE International Symposium on, Hangzhou, 2012, pp. 464-468.

9. I Nita R. Patne, Krishna L. Thakre "Factor Affecting Characteristics Of Voltage Sag Due to Fault in the Power System" Serbian Journal Of Electrical engineering. vol. 5, no.1, May2008, pp. 171-182

10. J. R. Enslin, "Unified approach to power quality mitigation," in Proc. IEEE Int. Symp. Industrial Electronics (ISIE '98), vol. 1, 1998, pp. 8-20

11. B. Singh, K. Al-Haddad, and A. Chandra, "A review of active filters for power quality improvement," IEEE Trans. Ind. Electron. vol. 46, no. 5, pp. 960-971, 1999

12. M. A. Hannan and Azah Mohamed, member IEEE, "PSCAD/EMTDC Simulation of Unified Series-Shunt Compensator for Power Quality Improvement", IEEE Transactions on Power Delivery, vol. 20, no. 2, April 2005

13. A. L. Olimpo and E. Acha, "Modeling and analysis of custom power systems by PSCAD/EMTDC," IEEE Trans. Power Delivery, vol. 17, no.1, pp. 266-272, Jan. 2002.

14. P. Pohjanheimo and E. Lakervi, "Steady state modeling of custom power components in power distribution networks," in Proc. IEEE Power Engineering Society Winter Meeting, vol. 4, Jan. 2000, pp. 2949-2954 